\title{
Disinfection of Wastewater by Infiltration-Percolation Coupled to UV Irradiation in an Arid Tunisian Area
}

Brahmi Mounaouer*, Fourti Olfa and Hassen Abdennaceur

Water Research and Technology Centre, Borj Cédria Science and Technology Park, Tunisia, University Tunis Cartage, Tunisia

\begin{abstract}
This paper aimed to the study of microbiological quality of wastewater effluents issued from a sand filter system used as a secondary treatment; this sand filter was coupled to UV irradiation system as a tertiary treatment to assume their possible application as alternatives to chemical disinfection of municipal wastewater before agronomic utilization. For that reason, an infiltration basin of $100 \mathrm{~m}^{2}$ of area equipped with two wells of sampling, in the center and in the periphery, has been constructed on the irrigated perimeter of Dissa in Gabes (south east of Tunisia). A comparative study was undertaken concerning the quality of effluents obtained from the sand filter as secondary effluent and from the UV irradiation disinfection system as a tertiary municipal wastewater treatment. Both the combined systems gave effluent of excellent microbiological quality (almost total absence of $E$. coli, faecal coliforms and $P$. aeruginosa). However, if the microbiological quality of effluent remained constant in the case of a sand filter system which depends only on the quality of the influent, while with the UV-disinfection process, microbiological quality of tertiary effluent was shown to depend on the quality of secondary effluent.

The monitoring of the UV irradiation device using a UV dose of around $96 \mathrm{~mW} . \mathrm{s} . \mathrm{cm}^{-2}$ and corresponding to an exposure time of $16 \mathrm{sec}$, for the secondary effluent at the outlet of Sand Filter, showed that the average bacterial inactivation rate was around $3 \mathrm{U}$-Log for $E$. coli, faecal coliforms and $P$. aeruginosa, respectively. Therefore, the average concentration remaining in the effluent at the output of the UV reactor, was less than a $100 \mathrm{cfu} / 100 \mathrm{ml}$ for $E$. coli and faecal coliforms, and less than a 100 bacteria/ $100 \mathrm{ml}$ for $P$. aeruginosa. These values coincided with the range recommended by several standardized international guidelines.
\end{abstract}

Keywords: Disinfection; Infiltration-percolation; Sand filter; UV reactor; Wastewater

\section{Introduction}

Reclamation and reuse of municipal wastewater have increased in recent years, largely due to lack of water resources and inadequate economic structures, particularly in arid and semi-arid countries [1]. However, the contamination of wastewater by pathogenic microorganisms represents a significant risk to public health. Poor water quality can cause illnesses such as gastroenteritis or upper respiratory infections, etc. Highly polluted water can occasionally cause serious diseases such as typhoid fever, dysentery, hepatitis, and cholera (USEPA) [2]. In this sense, to reduce this inconvenient, treated wastewater reuse must meet the microbiological and physicochemical standards recommended by international authorities to avoid damaging public health and the environment [1].

The use of treated wastewater is considered as an important alternative water resource. Although conventional treatment processes, i.e. primary treatment, disc filter and pressure sand filter are known to remove up to $99 \%$ of microorganisms that it is not sufficient to achieve requirements for wastewater discharge and wastewater reuse [3]. So, the disinfection is considered to be the primary operation of the inactivation or the destruction of pathogenic organisms and to prevent the spread of waterborne disease. On the other hand, the water disinfection efficiency depends on several factors: particularly an adequate contact time to ensure a sufficient decrease of microbial pathogens and a good water quality, the UV transmittance [4].

To date, chlorination is the most widely used procedure to inactivate pathogenic micro-organisms in water and wastewater, and it is the principal method for preventing waterborne infectious diseases throughout the world [1]. However, several studies have reported that the effectiveness of this process is reduced by turbidity, suspended solids and the presence of nitrogen compounds such as ammonia and nitrite [3]. Furthermore, the use of chlorine in wastewater gives rise to undesirable by-products suspected to pose a hazard to humans and the environment [5].

Infiltration percolation is a rustic and extensive purification technique that it is capable of completely oxidizing and decontaminating wastewater. Infiltration percolation is an extensive treatment process aimed to eliminate organic pollution, to oxidize ammonium and to remove pathogens [6]. This process has been increasingly used for the treatment of primary or secondary wastewater effluents because of its low energy and requirements maintenance [7]. The sand filter system revealed the problem of clogging by solids and other composites, which could be controlled daily through manual or chemical cleansing of the systems. This problem constitutes the main limitation for the application of this treatment system for municipal wastewater without forgetting the disponibility of great area to be occupied by the construction of a sand basin.

Currently, UV irradiation is considered as one of the best alternatives to chemical disinfection of water, especially chlorination [8]. This is justified when the water to be treated must fulfil certain

${ }^{*}$ Corresponding author: Brahmi Mounaouer, Water Research and Technology Centre, Borj Cédria Science and Technology Park, Tunisia, University Tunis Cartage, Tunisia, Tel./Fax: +21679 325 802; E-mail: brahmounaouer@yahoo.fr

Received July 12, 2013; Accepted August 08, 2013; Published August 14, 2013

Citation: Mounaouer B, Olfa F, Abdennaceur H (2013) Disinfection of Wastewater by Infiltration-Percolation Coupled to UV Irradiation in an Arid Tunisian Area. Hydrol Current Res 4: 155. doi:10.4172/2157-7587.1000155

Copyright: (C) 2013 Mounaouer B, et al. This is an open-access article distributed under the terms of the Creative Commons Attribution License, which permits unrestricted use, distribution, and reproduction in any medium, provided the original author and source are credited. 
Citation: Mounaouer B, Olfa F, Abdennaceur H (2013) Disinfection of Wastewater by Infiltration-Percolation Coupled to UV Irradiation in an Arid Tunisian Area. Hydrol Current Res 4: 155. doi:10.4172/2157-7587.1000155

Page 2 of 8

conditions to obtain an optimal effect of UV irradiation. This can be solved by the application, from the beginning, of a filtration system as disc filter or pressure sand filter that can enhance the quality of water such as turbidity, hardness, suspended solids, iron, manganese, humic acids. These later parameters of water quality are disruptive factors of UV disinfection (USEPA) [9].

The first aim of this work was to determine the performances of the Dissa infiltration percolation basin in the oxidation of organic matter and nitrogen. The second aim was to assess the microbiological quality of different effluents issued from sand filter, signalled by several authors as tertiary treatment. In contrast, in this study, these system worn as secondary treatment and ultraviolet technologies used as tertiary treatment in order to ameliorate the physical-chemical and microbiological characteristics of wastewater, respectively. The determination of the UV irradiation doses required to destroy E. coli, faecal coliforms and Pseudomonas aeruginosa from a secondary effluent provided by Gabes City wastewater treatment plant, for irrigation purposes, was a third objective.

\section{Materials and Methods}

\section{Experimental device}

Two phases of wastewater treatment were set in the operation: percolation-infiltration sand filter and UV irradiation disinfection monolamp reactor installed as shown in Figure 1. The experiments were conducted in $100 \mathrm{~m}^{2}$ sand filters located in the Dissa agriculture area in the north of Gabes City (southeast of Tunisia). The sand filter is a trapezoidal basin with $2 \mathrm{~m}$ in height and filled with $30 \mathrm{~cm}$ of coarse gravel and $1.5 \mathrm{~m}$ of sand. The mean grain size of sand (d50) is 0.26 $\mathrm{mm}$ and an effective size of $0.8 \mathrm{~mm}$ and of high uniformity $(\mathrm{Cu}=1.6)$. The filtration system operated with an upward flow at $5.0 \mathrm{~m}^{3} / \mathrm{m}^{2} \mathrm{~h}$ of hydraulic loading. Cleaning phase was manual, according to head loss (maximum $10 \mathrm{~m}$ ) and using filtrated water mixed with $10 \mathrm{mg} / \mathrm{l}$ of chlorine (Figure 1). A polyethylene pipe was used drilled with $0.5 \mathrm{~cm}$ holes to drain filtered water out.
In previous work of Boukchina et al., [10], the optimum hydraulic loading rate to improve primary wastewater quality by an intermittent sand filter for a single application was evaluated to $27 \mathrm{~cm} / \mathrm{d}$. In this study, the operational mode conditions rotated through a 7 -day cycle consisting of 4-day flooding period during which the basin received a volume of $27 \mathrm{~m}^{3} / \mathrm{d}$ of primary wastewater effluents, and a 3-day drying period during which the basin is allowed to dry out thoroughly. The wetting/drying operation is done for several purposes, mainly the maintenance of aerobic conditions in the upper soil layers [11].

The system was equipped with an automatic cleaning system according to head loss (maximum $20 \mathrm{~m}$ ), using filtrated water. A cleaning phase with chlorinated $(20 \mathrm{mg} / \mathrm{l})$ filtrated water was carried out daily. Feeding of each process was carried out through independent pumping, using water from secondary sedimentation effluent and in the range of ambient temperatures of 25 and $30^{\circ} \mathrm{C}$.

\section{Experimental methodology and analytical parameter determinations}

All the systems of percolation-infiltration operated continuously, and samples of water were taken manually and daily. Faecal coliforms, E. coli, and $P$. aeruginosa were analyzed as microbiological parameters in all water samples and some physico-chemical parameters, mainly chemical oxygen demand (COD), nitrates (N-NO3), Kjeldahl nitrogen (NTK), ammonium (N-NH4) and Phosphorus $\left(\mathrm{PO}_{4}^{3-}\right)$, were investigated during a period of 7 months of functioning of the sand filter systems. The techniques and methods followed for the collection, preservation and analysis were those given by (Rainwater and Thatcher, Brown et al., ICMR, Hem, APHA) [12-16]. Samples were analyzed for $\mathrm{pH}$ and electrical conductivity (EC) using a handheld $\mathrm{pH}$ and $\mathrm{EC}$ meter (HI 9811-0; Hanna Instruments, Woonsocket, RI) immediately after sample collection.

For bacteriological analysis, water samples were collected in sterile glass bottles of $1 \mathrm{~L}$ and analyzed immediately after collection within the 24 hours. The enumeration of thermotolerant coliforms (faecal

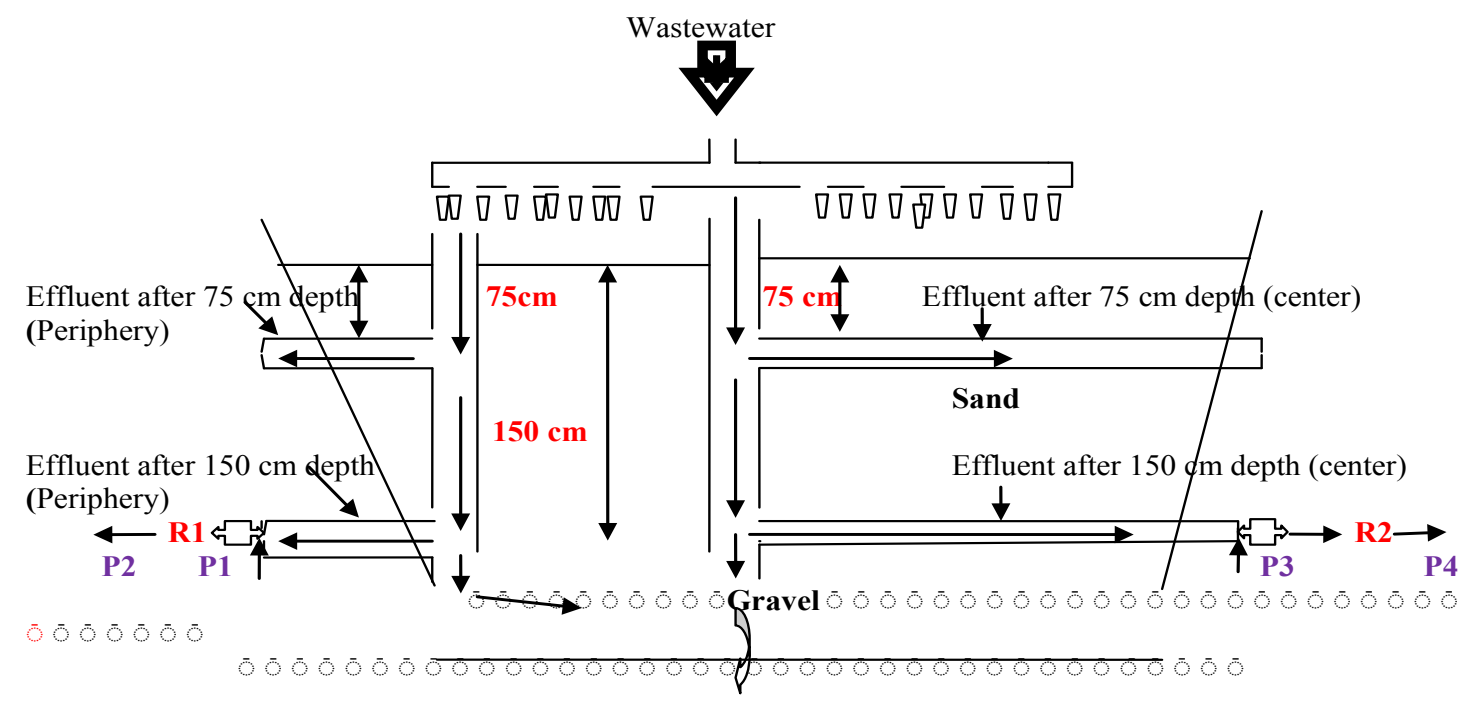

Filtered water

Figure 1: Presentation of the unit of infiltration-percolation couplet to UV irradiation system. R1 and R2: UV reactors intended for processing treated wastewater at $150 \mathrm{~cm}$ deep in the center and the periphery of the sand filter basin, respectively. 
coliforms) and E. coli was studied using the membrane filtration procedure according to ISO 9308-1 [17], using the double layer of tryptic-bile-agar and tryptic-soy agar (Difco), respectively. The colony count was calculated from the arithmetic mean of three membrane filter counts and expressed as colony forming unit (CFU).

All faecal coliforms isolated in the samples were identified using the bacterial identification system API 20 E (Bio Meriwux, Marcy d'Etoile, France).

On the other hand, the most-probable-number (MPN) technique was used for detecting and enumerating Pseudomonas aeruginosa in wastewater. Asparagine and acetamide broths were employed, respectively, as presumptive and confirmative MPN tests and as described in the 13th edition of Standard Methods for the Examination of Water and Wastewater (Anita and Robert) [18].

\section{Wastewater sampling and UV light treatments}

At a depth of $150 \mathrm{~cm}$ of the sand filter, in the center and in the periphery of the basin, two UV reactors referenced respectively $\mathrm{R} 1$ and R2, were installed at the output of two horizontally drum filters (Figure 1). One is transmitted from the periphery and the other of the center.

The UV irradiation device is a closed cylindrical steel reactor. It is equipped with a low-pressure mercury discharge lamp with a power of 15 Watts and protected by a quartz sleeve, placed in the axis of the irradiation room and emitting an average $\mathrm{UV}_{\mathrm{C}}$ light of around 25 $\mathrm{mW} . \mathrm{cm}^{-2}$ at wavelengths of $253.7 \mathrm{~nm}$.

Samples of the influent and the secondary effluent, deducted from the output of the sand filter, were collected in sterile glass bottles for microbiological analyses. A low-pressure $\mathrm{UV}_{\mathrm{C}}$ lamp of a power of 15 Watts was applied to treat a flow-rate from 500 to $1,100 \mathrm{l} / \mathrm{h}$, with nominal wavelength of maximum light intensity of $254 \mathrm{NM}$. This lamp had about $80 \%$ of the radiation around the maximum wavelength and the intensity was about $25 \mathrm{~mW} . \mathrm{cm}^{-2}$.

The installation was designed to treat a sample of $1.000 \mathrm{ml}$, irradiated for short periods of 6,10 and 16 seconds. According to these data, the doses provided were: 36,60 and $96 \mathrm{~mW} . \mathrm{s} . \mathrm{cm}^{-2}$, respectively. The second objective of this study is to apply later the UV dose able to give the highest abatement for each strain examined in the process of UV treatment in order to compare their rates of income during the various steps in the treatment plant. Before each treatment, the lamp was cleaned up with bidistilled water. After the irradiation, samples were ready for microbiological determinations. All irradiation experiments were performed at laboratory temperature of $(25 \pm 5)^{\circ} \mathrm{C}$.

\section{UV dose determination}

Definition and calculation of the efficient UV dose in the UV disinfection reactor are important and at the same time a difficult element to control [7].

Microbial inactivation depends on the $\mathrm{UV}_{\mathrm{C}}$ dose which is described as UV light intensity multiplied by the exposure time. As seen above, it is possible to calculate the intensity in $\mathrm{mW} . \mathrm{cm}^{-2}$ based on the assumed $\mathrm{UV}_{\mathrm{C}}$ power emission of the lamp. However, it is still necessary to control the exposure time of a particular particle (microorganism), during its passage through the irradiation chamber.

The dose of UV radiance $(D)$ expressed in $\mathrm{mW} . \mathrm{s.cm} \mathrm{cm}^{-2}$ in a point $X$ of the irradiation room is the product of the intensity (illumination) (I) of the radiation expressed in $\mathrm{mW} . \mathrm{cm}^{-2}$ in this point and the time of exposure (s) of water in the reactor $\left(t_{c}\right)$.

$$
D_{X}=I_{X} \cdot t_{c}
$$

Where, $D_{x}, I_{x}$ and $t_{c}$ are the dose in the point $X\left(\mathrm{~mW} . \mathrm{s.cm}{ }^{-2}\right)$, the UV intensity (illumination) in the point $X\left(\mathrm{~mW} . \mathrm{cm}^{-2}\right)$ and the time of exposure in second, respectively.

Or, In our approach and in order to model the hydrodynamic flow in the reactor and the short distance between the outlet of the filter and the UV reactor, the average residence time in the irradiation room of the UV reactor is calculated experimentally using the time of passage theoretically observed $(6,10$ and $16 \mathrm{sec})$ and for all flows tested without resorting to the technique of chemical tracing.

\section{Results and Discussion}

The performance of the sand filter system concerning the removal of physical-chemical parameters

During the experiment, COD of influent showed an average value of $235 \mathrm{mg} \mathrm{O}_{2} / \mathrm{l}$. The removal of the carbon is satisfactory during the winter with a mean output of $77 \%$ in the center of the basin and $65 \%$ in its periphery at $1.5 \mathrm{~m}$ depth. The depth of $75 \mathrm{~cm}$ allowed eliminating $50 \%$ of the COD in the center of the basin, and $40 \%$ in its periphery, with the remaining contents of the order of 83 and $94 \mathrm{mg} \mathrm{O} / \mathrm{l}$, respectively (Figure 2).

The result showed that the superficial layers of filter played an important role in the removal of the COD; therefore about $50 \%$ of the organic load is eliminated already after $75 \mathrm{~cm}$ of filtration depth. It is important to indicate that the carbon pollution constituted the principal factor in the development of microbial biomass in the filter. This biomass developed itself therefore less in the superficial layer depth and has important consequences on the management and the durability of the system. A depth of $150 \mathrm{~cm}$ appeared sufficient for the elimination of the organic matter. Bali et al. [19] showed also that the devices of infiltration were very effective for the removal of the wastewater organic matter content, and that the major part of removal took place in the superficial layers of the filter.

The average concentration of orthophosphates registered in the influent during the period of study was about $52 \mathrm{mg} / \mathrm{L}$. The depth of $75 \mathrm{~cm}$ allowed removing about $50 \%$ of the phosphorus in the center of the basin, and around $62 \%$ in its periphery. The elimination of the phosphorus was relatively variable for the same depth; it was higher in the periphery than in the center of the basin. The outputs reached $62 \%$ at $75 \mathrm{~cm}$ and $75 \%$ at $150 \mathrm{~cm}$ depth; therefore the global output pass extensively out of the basin and it is about $25 \%$. According to Metal, the performances of the systems of infiltration-percolation in the elimination of the orthophosphates depend on electro-chemical conditions of the mass filter, and soon the mineralogical composition of the sand filter.

Organic nitrogen and ammonium contents revealed good performance process in the removal of nitrogen pollution. The retention of the Kjeldahl nitrogen is highly effective during the period of drying. Approximately $95 \%$ of this nitrogen was retained in the sand filter. On the other hand, we have not registered sensitive variations of the total nitrogen remaining in the percolate at different depths. At $75 \mathrm{~cm}$ depth, the elimination of total nitrogen is already raised with an output of $85 \%$ in the center and $78 \%$ in the periphery of the basin, and the contents are 4.8 and $6.1 \mathrm{mg} / \mathrm{l}$, respectively. At $150 \mathrm{~cm}$ of filter depth, the total nitrogen has been eliminated at the rate of $96 \%$ in the center and $92 \%$ in the periphery, with average vestigial contents of 1.4 and $2 \mathrm{mg} / \mathrm{L}$, 
Citation: Mounaouer B, Olfa F, Abdennaceur H (2013) Disinfection of Wastewater by Infiltration-Percolation Coupled to UV Irradiation in an Arid Tunisian Area. Hydrol Current Res 4: 155. doi:10.4172/2157-7587.1000155

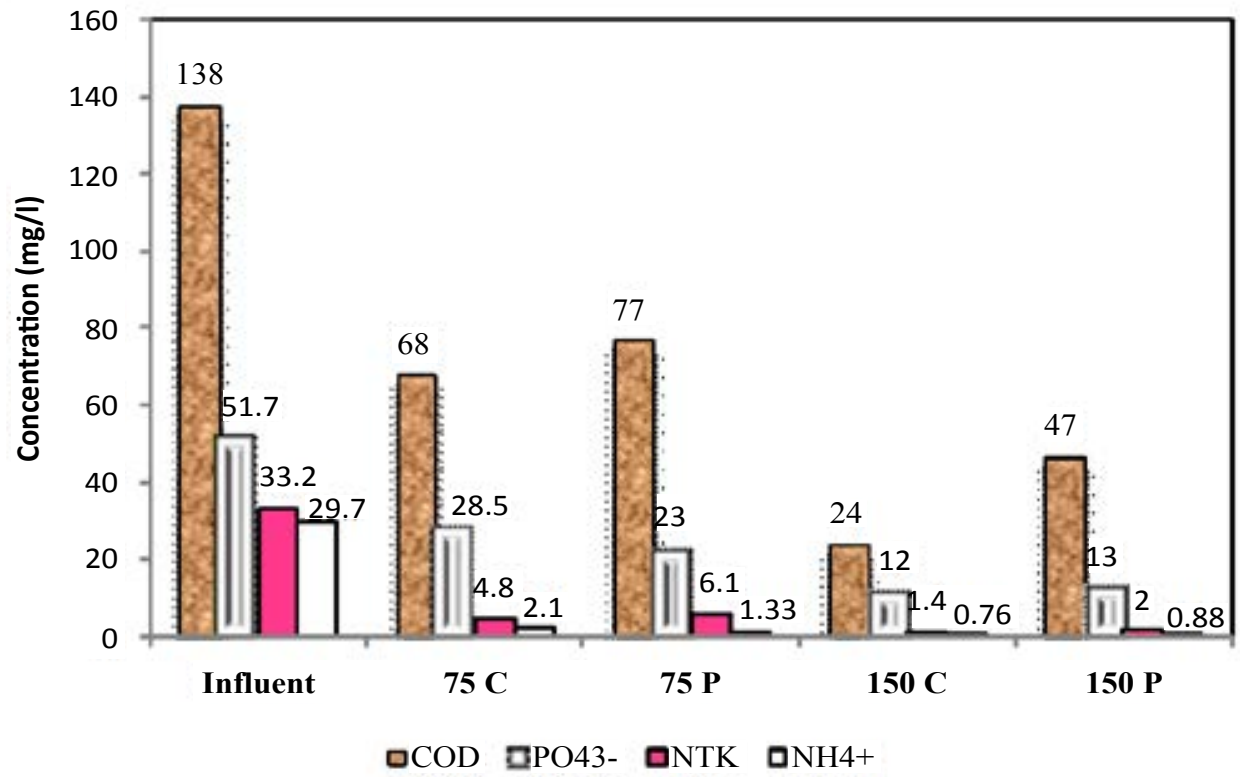

Figure 2: Concentration of $\mathrm{COD}$, of $\mathrm{PO}_{4}{ }^{3-}$ and of nitrogen pollution in the influent and in the effluent sampled at $75 \mathrm{~cm}$ filter depth. Legend: $\mathrm{C}$ : Center

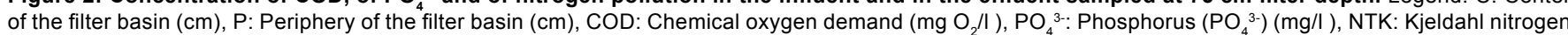
(NTK) (mg/l ), $\mathrm{NH}_{4}^{+}$: Ammonium (N-NH4) (mg/l ).

respectively. The nitrification at $75 \mathrm{~cm}$ of depth was globally similar to the one of $150 \mathrm{~cm}$. The content of the filtrated water in nitrates was around $15 \mathrm{mg} / \mathrm{L}$ whereas it reached $30 \mathrm{mg} / \mathrm{L}$ at the depth of $75 \mathrm{~cm}$. The increase of nitrate content observed at $75 \mathrm{~cm}$ depth as compared to the one registered at $150 \mathrm{~cm}$ could be explained by an operation of washing of the nitrates accumulated in the sand filter during the previous drainage period, and also it may come from oxidization of ammonium adsorbed during the previous alimentation. These results confirmed the ones of Bancole [20] that proved a big part of the nitrogen will be fixed in the first centimeter layer of the sand filter.

\section{Abatement of bacteria in the sand filter system according to the depths}

The removal of the fecal Coliform, Esherichia coli and the $P$. aeruginosa recorded in treated wastewater was an average of about 1 Ulog (90\%). The residence times of wastewater in the sand filter was short, in the score of minutes that follow the application of the volume of wastewater; the porous character of the mass filtering was saturated by the very loaded water in organic matter. Indeed, these surroundings are not favorable to the elimination of bacteria. The bacteriological criteria of no restraining treated wastewater reuse are satisfied extensively. Therefore at $75 \mathrm{~cm}$ of depth filter, the bacterial abatement was on average around $3 \mathrm{Ulog}$, and the last $75 \mathrm{~cm}$ of the sand filter played an essential role in the sanitary quality of treated wastewater. This result is comparable to that found by Bali et al. [19] in a similar percolation-infiltration study. These authors attributed the microbial removal to the real residence time in the sand filter, and to the temperature of water. Therefore after 15 days of drying (aeration, ventilation), we noted a better tendency to decrease the number of these bacteria in treated water at different depths (Figure 3). Indeed, the microbiological quality of the filtrate is slightly better than the one registered in the influent with a tendency of the maximum removal rate in the center of the filter basin than in the periphery, and this tendency was valuable for all depths. So, it seemed that the logarithm of the concentration of the bacteria decreases in a linear way according to the filter depth and this result was confirmed by the work of Bancole [20]. According to the study of Bali et al. [19], it was the height of the unsaturated part of the sand filter that would affect the removal rate of microorganisms in the similar filter system. This fact would be due to the increase of the residence time in a sand filter system in accordance with the amplification of the filtration depth.

Despite this apparently average percentage, for a $N_{o}$ of $10^{7} \mathrm{CFU} / \mathrm{ml}$ on average for different bacteria studied, and although strong retention of up to $10^{4}$ colonies / $\mathrm{ml}$ for some strains, the number $10^{3}$ colonies / $\mathrm{ml}$ remaining could cause serious health and environmental problems [17].

\section{Microbiological validation of the UV reactor}

In principle, the disinfection performance of a UV reactor is determined based on a series of microbial challenges that are conducted either on full or pilot-scale. During a validation, the UV system is evaluated according to various operational conditions, which may include mainly the water flow rate, the UV lamp power (or relative lamp output), and the number of operational lamps (monoor multi-lamps system). During each test, samples are collected from the influent and effluent of the UV reactor to quantify the microbial abatement associated with the specific operational conditions.

In this study, and as it was shown in Figure 4, the log reduction tendency for faecal coliforms, $P$. aeruginosa and E. coli, respectively, at the center of the filtering basin and in its periphery at the depth of 150 $\mathrm{cm}$ and according to different UV dose applied. It can be observed that $P$. aeruginosa appeared more UV resistant than faecal coliforms and $E$. coli, because a higher log reduction of 4 and 3 U-Log respectively, for E. coli and faecal coliforms occurred after an exposure of 16 seconds that corresponds to a dose of $96 \mathrm{~mW} . \mathrm{s}_{\mathrm{cm}} \mathrm{cm}^{-2}$. In contrast, after the same exposure time, the log reduction has not exceeded $2 \mathrm{U}$-Log for $P$. aeruginosa.

On the other hand, several standardized international guidelines 
Citation: Mounaouer B, Olfa F, Abdennaceur H (2013) Disinfection of Wastewater by Infiltration-Percolation Coupled to UV Irradiation in an Arid Tunisian Area. Hydrol Current Res 4: 155. doi:10.4172/2157-7587.1000155

Page 5 of 8
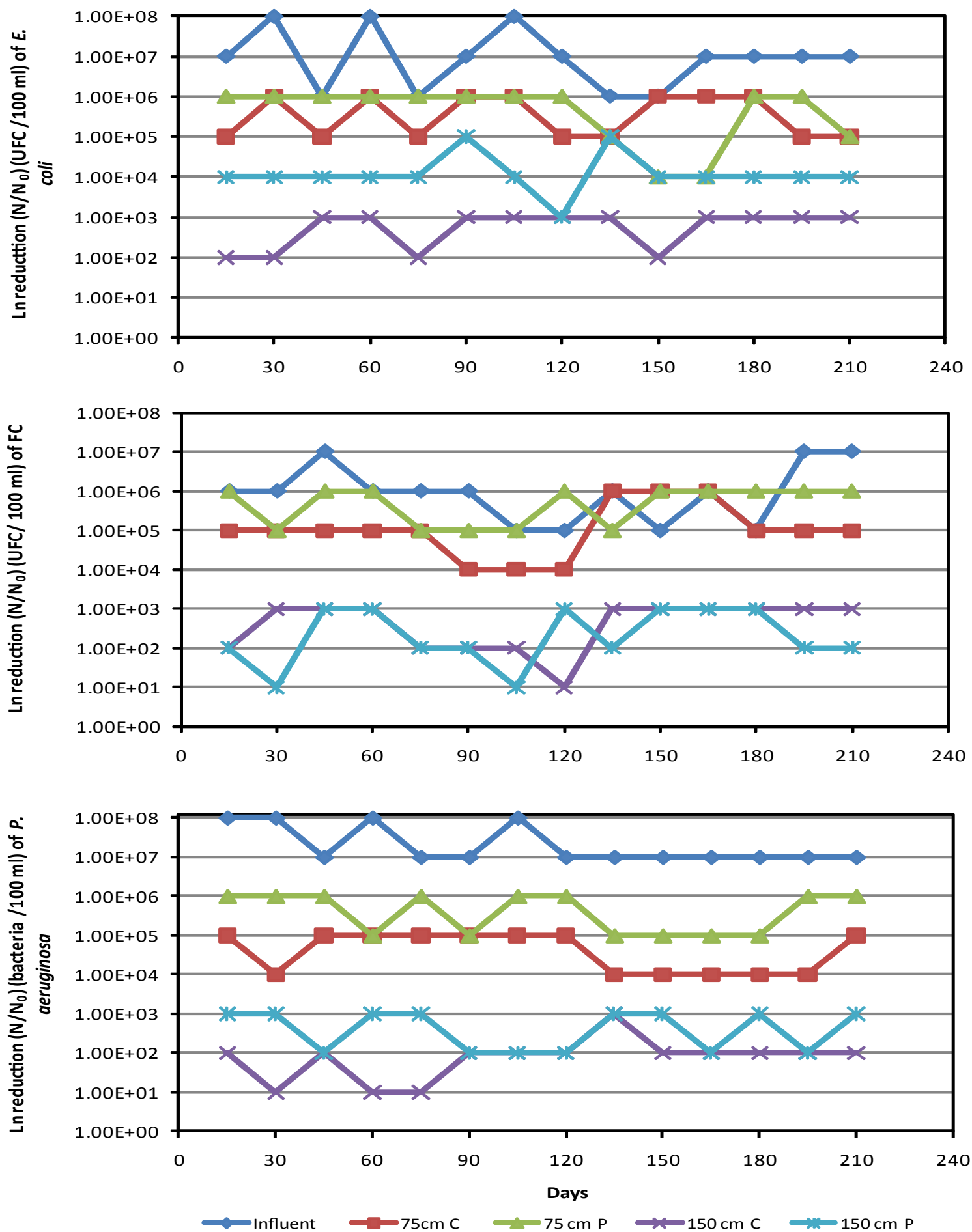

Figure 3: Removal of $E$. coli, of CF and of $P$. aeruginosa at $75 \mathrm{~cm}$ filter depth in the center and in the periphery of the basin of the infiltration-percolation.

stipulate that the reuse of wastewater requires a decrease in the number of indicators bacterial of about 3 U-log [21]. However, the complexity of current processes and requirements for environmental safety, microbiology, public health and even industry, require the introduction of advanced monitoring systems based on monitoring methodologies built on the principle of analytical redundancy. For this reason, a second standard requires a reduction ratio of the number of $P$. aeruginosa of the order of $5-\log$ for treated wastewater reuse [8]. These waters are loaded prior to about $10^{7} \mathrm{CFU} / 100 \mathrm{~mL}$ of $P$. aeruginosa.

Similarly, and since it was mentioned in Figure 4, all inactivation processes showed a linear portion whatever the dose, despite the lowest correlation coefficient for some adjustments. In this sense, to improve 

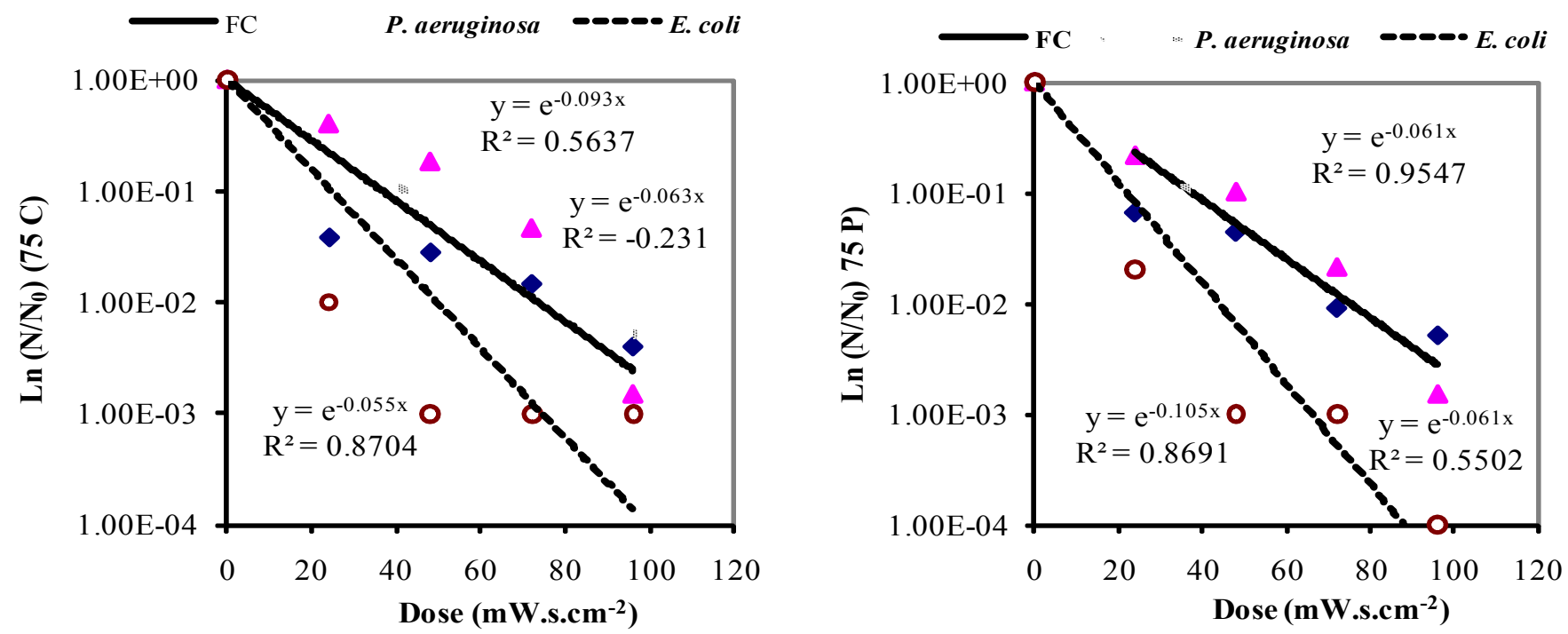

Figure 4: Inactivation rates of $E$. coli, of fecal coliforms and of $P$. aeruginosa (log reduction), following UV irradiation at the depth of $150 \mathrm{~cm}$ in the center and in the periphery of the basin and at different UV dose. y: Reduction $=N / N_{0}$ with $N$; Number of micro-organisms at the instant $T ; N_{0}$; Number of micro-organisms at the instant $T=0$; Dose $\left(\mathrm{mW} . \mathrm{s} . \mathrm{cm}^{-2}\right)=$ UV Intensity $\left(\mathrm{mW} . \mathrm{cm}^{-2}\right)$. Time of contact $(\mathrm{s})$.

some of these adjustments, a linear regression was calculated only with data obtained at lower UV doses $\left(<48 \mathrm{~mW} . \mathrm{s} . \mathrm{cm}^{-2}\right)$, the correlation coefficient slightly improved for $E$. coli from 0.87 up to 0.92 , for faecal coliforms from 0.55 up to 0.58 , and for P. aeruginosa form 0.97 up to 0.98 , leading to a better fitting (Results not shown). AENOR Water Quality [22] has reported a gradual flattening at higher UV doses, often attributed to particulate matter in the wastewater. This is consistent with the need to apply UV radiations to wastewater previously clarified, in order to avoid the effect of particles [1].

Because the UV dose provided is a complex function of many variables, UV reactor validation is used to demonstrate the disinfection effectiveness of the system.

As illustrated in Figure 4, an almost total removal of these indicators would be achieved with doses over $96 \mathrm{~mW}$.s. $\mathrm{cm}^{-2}$ corresponding to a UV exposure of $16 \mathrm{sec}$. Therefore, the use of a dose of $96 \mathrm{~mW} . \mathrm{s.cm}^{-2}$ is necessary, firstly to calculate the performance of the UV reactor, and secondly to obtain treated wastewater free from microbes and meets the standards recommended by several standardized international guidelines.

This figure showed that the removal rate for all strains increased according to the UV time exposure. In this sense, samples irradiated during $4 \mathrm{sec}$ achieved a reduction of $E$. coli, of faecal coliforms and of $P$. aeruginosa, being of 97 , of 94 and of $78 \%$, respectively. These removal percentages changed for E. coli from 94 up to $96 \%$, for faecal coliforms from 78 up to $80 \%$, and for P. aeruginosa from 97 up to $99 \%$, in the case of $8 \mathrm{sec}$ of UV exposure. After 12 or $16 \mathrm{sec}$, the totality of E. coli, of faecal coliforms and of P. aeruginosa completely disappeared from the growth medium. Data fitted to an exponential equation, with correlation coefficients of (0.78- 0.89) for E. coli, (0.96-0.96) for faecal coliforms, and (0.57-0.66) for $P$. aeruginosa, on behalf of water sampled at the output of at $150 \mathrm{~cm}$ of filtration depth in the center and in the periphery of the basin, respectively.

At $150 \mathrm{~cm}$ depth, the quality of the filtrate is slightly better than the influent with still tendency to higher removal in the center than in the periphery of the basin. In addition, an average abatments of bacteria in the center than in the periphery of the basin were calculated for $E$. coli (64 and 62\%) $i$, faecal coliform (50 and 46\%) and P. aeruginosa (62.5 and $59.5 \%)$, respectively.

Figure 5 illustrated the UV inactivation rates for all the types of bacteria considered at the depth filter of $150 \mathrm{~cm}$, in the center and in the periphery of the filter basin and using different UV doses, respectively.

The UV irradiation device presented the best microbial removal percentages at $6 \mathrm{sec}$ of UV exposure time, with $87 \%$ for E. coli, $84 \%$ for faecal coliforms and with $87.5 \%$ for $P$. aeruginosa. With an exposure time of 10 or $16 \mathrm{sec}$, almost all E. coli, faecal coliforms and P. aeruginosa disappeared completely from the culture media.

This ultraviolet dose is much higher than that reported by Gómez et al. [1], who indicated a value over $35 \mathrm{~mW} . s . \mathrm{cm}^{-2}$ for total elimination $(N / N=0)$ of faecal coliforms, of $E$. coli and of coliphages from urban wastewater. These authors used a physical-chemical treatment prior to UV disinfection, assuring an effluent with excellent quality, and $99 \%$ of turbidity removal. In this case and based on the curves of Figure 4, a dose of $35 \mathrm{~mW} . \mathrm{s.cm} \mathrm{cm}^{-2}$ would remove only 37.2 up $50 \%$ of E. coli, 27 up $37.5 \%$ of faecal coliform and 10 up $17.5 \%$ of $P$. aeruginosa, as an average. These results are also consistent with those reported by Andreakis et al. [23] who found a significant increase in UV disinfection efficiency with samples sand-filtered. The implementation of UV disinfection facilities in secondary effluents needed a previous treatment in order to reduce suspended solids and turbidity in the wastewater. Sharrer et al. [24] reported a complete inactivation of coliform bacteria at approximately $77 \mathrm{~mW} . \mathrm{s.cm}^{-2}$, in a recirculating salmonid culture system. However, these authors indicated that total heterotrophic bacteria in the recirculating system required a UV dosage in excess of $1800 \mathrm{~mW} . \mathrm{s.cm}^{-2}$ to achieve a not quite $2 \log _{10}$ reduction. Macauley et al. [25] reported an irradiation time of 10 minutes for a total bacteria reduction to less than $1000 \mathrm{cfu} / \mathrm{ml}$ in a lagoon with swine wastewater, corresponding to effective doses of 220 and $770 \mathrm{~mW}$.s. $\mathrm{cm}^{-2}$ for two lagoons. These authors reported that this technology is unlikely to be economically feasible, due to its high energy consumption. In our experiments, UV doses have been always less than $100 \mathrm{~mW}$.s.cm ${ }^{-2}$. According to Figures 
Citation: Mounaouer B, Olfa F, Abdennaceur H (2013) Disinfection of Wastewater by Infiltration-Percolation Coupled to UV Irradiation in an Arid Tunisian Area. Hydrol Current Res 4: 155. doi:10.4172/2157-7587.1000155

Page 7 of 8
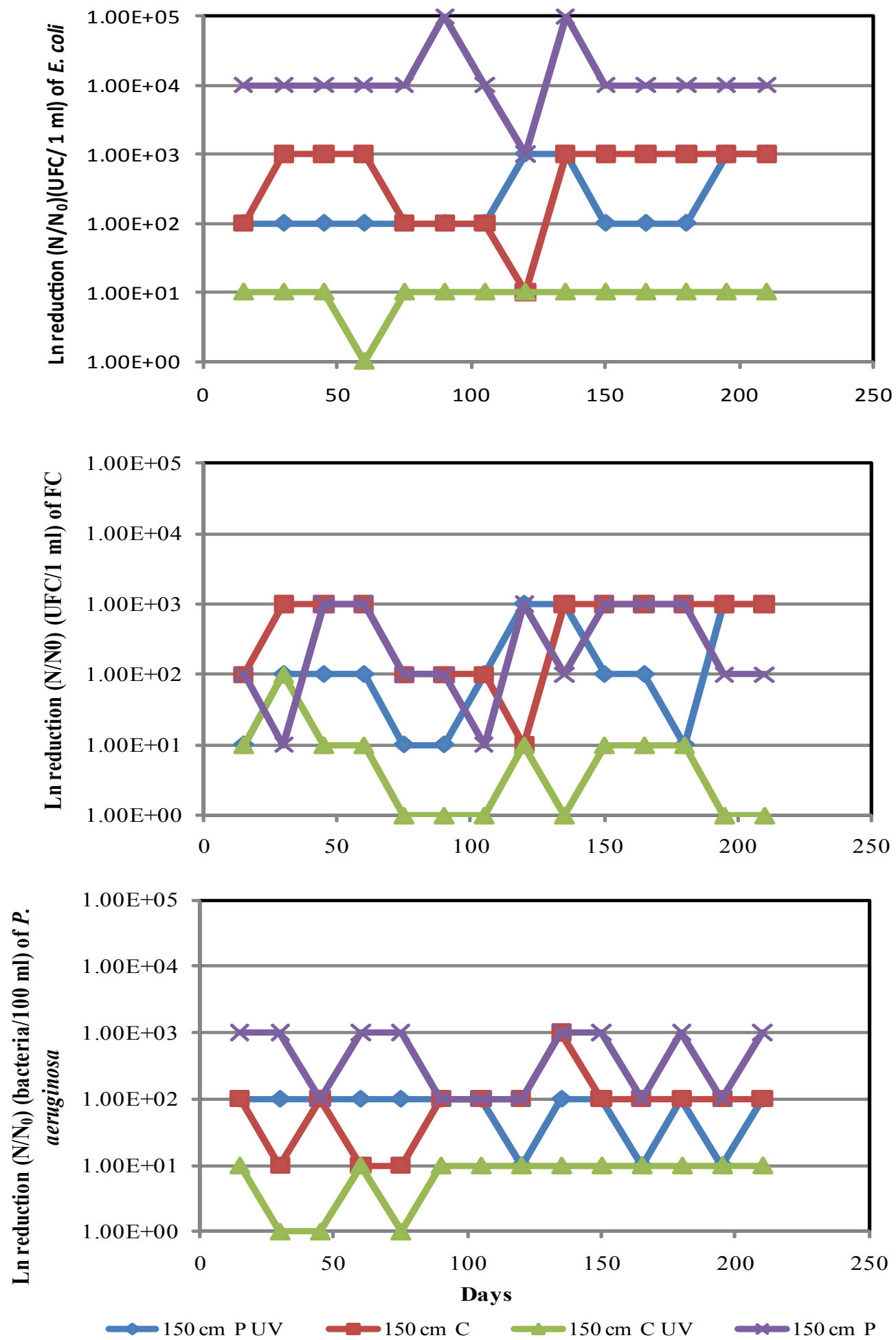

Figure 5: Removal of $E$. coli, of $C F$ and of $P$. aeruginosa following coupled treatment by infiltration percolation in the center (C) and in the periphery $(\mathrm{P})$ of the basin and UV irradiation.

4, a reduction down to $1000 \mathrm{cfu} / 100 \mathrm{ml}$ for $E$. coli and faecal coliform or 1000 bacteria $/ 100 \mathrm{ml}$ for $P$. aeruginosa would need a dose over $24 \mathrm{~mW} . \mathrm{s} . \mathrm{cm}^{-2}$ for all types of bacteria examined. A high removal of these indicators would be achieved with doses over $96 \mathrm{~mW} . \mathrm{s.cm}{ }^{-2}$
In this sense, the daily microbiological monitoring of the performance of the UV reactor (R1) by the use of a dose of $96 \mathrm{~mW} . \mathrm{s} . \mathrm{cm}^{-2}$, corresponding to an exposure of $16 \mathrm{sec}$, at the depth of $150 \mathrm{~cm}$ and in the center of the basin was finalized and shown in Figure 5. Therefore, 
Citation: Mounaouer B, Olfa F, Abdennaceur H (2013) Disinfection of Wastewater by Infiltration-Percolation Coupled to UV Irradiation in an Arid Tunisian Area. Hydrol Current Res 4: 155. doi:10.4172/2157-7587.1000155

the average concentration remaining in the effluent at the output of the $\mathrm{UV}$ reactor ( $\mathrm{R} 1$ or $\mathrm{R} 2)$ at $150 \mathrm{~cm}$ depth was less than $100 \mathrm{cfu} / 100 \mathrm{~mL}$ of E. coli, and of faecal coliform. For P. aeruginosa, the number of bacteria remained was less than 100 bacteria/ $100 \mathrm{~mL}$; this value coincides with the range recommended by several standardized international guidelines [8]. Similarly, Figure 5 showed that the microbiological quality of the filtrated water collected in the center at the depth of 150 $\mathrm{cm}$ and at the output of the UV reactor (R1) was slightly better than the one registered in the periphery of the basin (R2).

\section{Conclusions}

A great physical-chemical and microbiological performance sand filter in the region of Dissa was reported. Results confirmed that this technique is performed as an advanced treatment system for COD and nitrogen. The experimental study has shown the influence of the filter depth on the output purification of the process. On the other hand, the elimination of the orthophosphate depends on electro-chemical conditions of the sand massif and not too much the thickness of this sand filter. Water quality analyses demonstrated that oxidation activity was mainly located in upper sand layers. Maintaining infiltration surface evenness helps provide uniform infiltration. The UV inactivation rates of $E$. coli, of faecal coliforms and of $P$. aeruginosa (log reduction) obtained, respectively, at the output and at $150 \mathrm{~cm}$ of filtration depth in the center and in the periphery of the basin have allowed increasing the average rate of elimination of feacal bacteria of about 1 Ulog. The combination of UV irradiation with the technique of infiltration percolation constituted a final step with the aim of removing pathogen microorganisms from the effluents of conventional wastewater treatment plants. It is a method that can be used to improve water quality for possible reuse in unrestricted irrigations.

\section{Acknowledgements}

This study is supported by the European Union (Avicenna Project $n^{\circ}$ 93AVI054). We express great appreciation to all the team of the laboratory of Wastewater Treatment, Borj-Cedria techno-park that contributed to realize this work, particularly Mr Aissaoui, Mr Hachemi and Ms Mabrouki for their help.

\section{References}

1. Gómez AF, Plaza G, Garralón J, Pérez MA, Gómez (2007) A comparative study of tertiary wastewater treatment by physico-chemical-UV process and macrofiltration-ultrafiltration technologies. Desalination 202: 369-376.

2. US Environmental Protection Agency (2006) Performance of storm water retention ponds and constructed wetlands in reducing microbial concentrations. EPA/600/R-06/102.

3. Lazarova V, Savoye P, Janex MI, Bletchley ER III, Pommepuy M (1999) Advanced wastewater disinfection technologies: state of the art and perspectives. Water Sci Tech 40: 203-214.

4. Sommer R, Haider T, Cabaj A, Pribil W, Lhotsky M (1998) Time dose reciprocity in UV disinfection of water. Water Sci Tech 38: 145-150.

5. Minear RA, Amy GL (1996) Disinfection by-Products in Water Treatment: The Chemistry of Their Formation and Control, Lewis, New York, pp. 502.

6. Faby JA, Brissaud F, Bontoux J (1999) Wastewater Reuse in France: Water Quality Standards and Wastewater Treatment Technologies. Water Sci Tech 40: $37-42$.

7. Asano T, Cotruvo JA (2004) Groundwater recharge with reclaimed municipal wastewater: health and regulatory considerations. Water Res 38: 1941-1951.

8. Meiting GUO, Hongying HU, Wenjun LIU (2009) Preliminary investigation on safety of post-UV disinfection of wastewater: bio-stability in laboratory-scale simulated reuse water pipelines. Int J Sci Tech Desalting Water Purif 239: 2228.

9. USEPA (2003b) Voluntary National Guidelines for Management of On-site and Clustered (Decentralized) Wastewater Treatment Systems. EPA, 832-B-03001, pp. 62.

10. Boukchina R, Makni H, Abdedaïem S, Brissaud F (2003) Amélioration de la Réutilisation Des Eaux Usées en Régions Arides Tunisiennes. Hydrotop 146148.

11. Gill LW, O'Súlleabháin C, Misstear BD, Johnston PJ (2007) The treatment performance of different subsoils in Ireland receiving on-site wastewater effluent. J Environ Qual 36: 1843-1855.

12. Rainwater FH, Thatcher LL (1960) Methods for Collection and Analysis of Water Samples. US Geol Surv Water Supply Papers 1454: 1-301.

13. Brown E, Skougstad MW, Fishman MJ (2011) Methods for collection and analysis of water samples for dissolved minerals and gases. Techniques of Water Resources Investigations of the United States Geological Survey, Int J ecosyst 1: 1-9.

14. Indian Council of Medical Research (ICMR) (1975) Manual of Standards of Quality for Drinking Water Supplies.

15. Hem JD (1985) Study and Interpretation of Chemical Characteristics of Natural Water. US Geological Survey, Washington, USA.

16. American Public Health Association (APHA) (1995) Standard Methods for Estimation of Water and Wastewater. 19th Ed., American Water Works Association, Water environment Federation, Washington.

17. Brahmi M, Belhadi NH, Hamdi H, Hassen A (2010) Modeling of secondary treated wastewater disinfection by UV irradiation: effects of suspended solids content. J Environ Sci (China) 22: 1218-1224.

18. Anita KH, Robert LA (1975) Evaluation of a Most Probable-Number Technique for the Enumeration of Pseudomonas aeruginosa. Appl Microbiol 30: 596-601.

19. Bali M, Gueddari M, Boukchina R (2010) Treatment of Secondary Wastewater Effluents by Infiltration Percola- tion. Desalination 258: 1-4.

20. Bancolé A (2001) Oxidation by Infiltration Percolation. Doct Thesis, Montpellier II University, Montpellier Cedex.

21. Brahmi M, Hassen A (2011) Disinfection of Wastewater by UV Irradiation: Influence of Hydrodynamics on the Performance of the Disinfection. Environ Eng Res 258: 243-252.

22. AENOR Water Quality (2002) Asociación Española de Normalización y Certificación. Madrid.

23. Andreakis A, Mamais D, Christoulas D, Kabylafka S (1999) Ultraviole disinfection of secondary and tertiary effluent in the Mediterranean region. Water Sci Technol 40: 253-260.

24. Sharrer MJ, Summerfelt ST, Bullock GL, Gleason LE, Taeuber J (2005) Inactivation of bacteria using ultraviolet irradiation in a recirculating salmonid culture system. Aquacult Eng 33: 135-149.

25. Macauley JJ, Qiang Z, Adams CD, Surampalli R, Mormile MR (2006) Disinfection of swine wastewater using chlorine, ultraviolet light and ozone. Water Res 40: 2017-2026. 